Romeu Gomes 1

\title{
Avaliação da assistência ambulatorial a portadores de HIV/AIDS no Rio de Janeiro, segundo a visão de seus usuários
}

\author{
Evaluation of outpatient care for people \\ with HIV/AIDS in Rio de Janeiro, from the \\ user's perspective
}

Cosme Marcelo Furtado Passos da Silva 2

Suely Ferreira Deslandes 1

Edinilsa Ramos de Souza 2

\footnotetext{
1 Instituto Fernandes Figueira, Fundação Oswaldo Cruz. Av. Rui Barbosa 716 2o andar, Flamengo, Rio de Janeiro, $R J$ 22250-020, Brasil. 2 Centro Latino Americano de Estudos de Violência e Saúde "Jorge Carelli", Departamento de Epidemiologia e Métodos Qualitativos em Saúde, Escola Nacional de Saúde Pública, Fundação Oswaldo Cruz. Av. Brasil 4036, 7o andar, Manguinhos, Rio de Janeiro, RJ, 21040-360, Brasil.
}

\begin{abstract}
This article analyzes perceptions by people with HIVIAIDS towards five specialized units under the State Health Department, Rio de Janeiro, concerning the care provided there. The research was based on both quantitative and qualitative methods. Data from 228 questionnaires and 19 semi-structured interviews were analyzed. The results generally indicated a positive evaluation on the part of this group of health care users. One conclusion was that the positive evaluation was actually related to the quality of the services available to them. However, users seem to have low expectations toward the level of services public clinics generally provide.

Key words Ambulatory Care; Outpatients; Acquired Immunodeficiency Syndrome; HIV

Resumo Este artigo analisa a percepção de portadores de HIVIAIDS de cinco serviços especializados do Estado do Rio de Janeiro, acerca da assistência que lhes é prestada. A metodologia da pesquisa foi baseada nas abordagens quantitativa e qualitativa. Foram analisados os dados de 228 questionários, preenchidos pelos sujeitos, e 19 entrevistas semi-estruturadas. Os resultados afirmaram, de forma geral, uma avaliação positiva. Concluiu-se que esta avaliação pode estar referindo realmente a boa qualidade do atendimento prestado. No entanto, os usuários parecem ter expectativas baixas no que diz respeito ao tipo de serviço que centros públicos podem prover. Palavras-chave Assistência Ambulatorial; Pacientes Ambulatoriais; Síndrome da Imunodeficiência Adquirida; HIV
\end{abstract}




\section{Introdução}

Este artigo é parte de uma pesquisa que teve como objetivo geral avaliar a adesão dos usuários ao serviço de assistência ambulatorial a portadores de HIV/AIDS (Rio de Janeiro, 1998), como um dos parâmetros da qualidade das ações oferecidas. Nela, foram contemplados princípios de avaliação da qualidade de serviços de saúde segundo os quais se consegue um melhor cuidado de saúde ao se maximizar o bem estar do paciente, considerando o balanço de perdas e ganhos esperados, presentes no processo de cuidado oferecido em todas as suas etapas (Donabedian, 1984). Nesse sentido, a referência não é um estado de saúde, mas sim as melhorias no estado de saúde conseguidas dentre as melhorias possíveis.

A avaliação, iniciada em dezembro de 1997 e concluída em junho de 1998, foi promovida pela Coordenação Nacional de DST/AIDS - Ministério da Saúde (CN-DST/AIDS), Coordenações Estadual e Municipal de DST/AIDS do Rio de Janeiro e Fundação Municipal de Saúde de Niterói. Utilizou-se como parâmetro para a avaliação dos serviços estudados os princípios que orientaram a criação dos Serviços de Assistência Especializada - SAE da CN - DST/AIDS (MS, s/d; MS, 1997a). Apesar de se ter consciência do fato de que estes serviços nem sempre foram criados com base nesses princípios, uma vez que grande parte deles se situa em estruturas que seguem outras diretrizes, entendeu-se que a orientação do SAE pode servir de referência, na medida em que esta sintetiza as diretrizes nacionais da assistência a portadores de HIV/AIDS.

A adesão foi entendida, na pesquisa, como a participação do usuário nas atividades multiprofissionais propostas, o reconhecimento e a adoção das orientações preconizadas (na medida da correspondência entre os objetivos da assistência e as expectativas de sua clientela). Duas dimensões perpassaram a avaliação: o que se oferece e como se oferece. Assim, tanto a qualidade técnica da assistência como as relações estabelecidas entre beneficiários e profissionais assumiram um papel fundamental para a pesquisa.

Este artigo, enquanto um recorte da pesquisa original, tem como objetivo analisar a percepção de portadores de HIV/AIDS, que freqüentavam cinco unidades de serviços especializados do Estado do Rio de Janeiro, acerca da assistência que lhes era prestada. Optou-se por trabalhar com a ótica dos usuários sobre a qualidade da assistência prestada por considerá-la um dos indicadores centrais para avaliar a adesão aos serviços. Acredita-se que essa análise possa contribuir para que a assistência ofereça um atendimento mais próximo às necessidades e expectativas desses usuários.

\section{Metodologia}

O desenho metodológico da pesquisa original fundamentou-se na articulação e complementaridade das abordagens quantitativa e qualitativa, conforme recomendação de Minayo \& Sanches (1993). O estudo partiu, portanto, do princípio de que “(...) junto com os dados quantitativos e com o conhecimento técnico-científico das doenças, qualquer ação de prevenção, tratamento e de planejamento de saúde necessita levar em conta valores, atitudes e crenças de uma população" (Minayo, 1991:233), objetivando "estabelecer os parâmetros de uma ação mais localizada, mais personalizada e em conjunto com a população a que se destina" (Minayo, 1991:237).

Fundamentada nessa perspectiva, a avaliação seguiu os princípios de Denzin (1970) que propõe a triangulação, entendida como a combinação de (a) diferentes fontes de dados; (b) diferentes técnicas de investigação; e (c) diferentes concepções acerca do objeto de estudo.

Para os objetivos deste artigo foram utilizados alguns dos dados coletados para a pesquisa original em cinco serviços de assistência ambulatorial a portadores de HIV/AIDS. Esses serviços foram indicados para inclusão no estudo por serem considerados como referência no Estado. São eles: (1) Centro Municipal de Saúde Manoel José Ferreira (CMS - Catete); (2) Centro Municipal de Saúde Píndaro de Carvalho Rodrigues (CMS-Gávea); e (3) Setor de Doenças Infecciosas e Parasitárias do Hospital Pedro Ernesto da Universidade do Estado do Rio de Janeiro (DIP-UERJ); (4) Policlínica de Especialidades Centro Previdenciário de Niterói (CPN), no Município de Niterói; (5) Serviço de DST/ AIDS do Hospital Geral de Nova Iguaçu (HGNI), no Município de Nova Iguaçu.

Todos esses serviços oferecem o atendimento de clínica médica e de serviço social. O serviço de psicologia só não era oferecido nos dois centros municipais de saúde. Nenhum serviço oferecia consulta de enfermagem. A odontologia só era oferecida pelo CPN.

No presente estudo foram analisados os dados dos seguintes instrumentos: (1) questionário preenchido por usuários com mais de uma consulta, constituído de cinco blocos temáticos (caracterização dos usuários; acesso aos serviços; acolhida dos profissionais; utilização dos 
serviços e a avaliação da qualidade de assistência); (2) entrevista semi-estruturada realizada com 19 usuários (abordando as seguintes temáticas: motivações para a procura dos serviços; avaliação da assistência prestada; principais dificuldades para adesão às atividades e orientações dos serviços; expectativas e sugestões para a melhoria do serviço).

A fim de viabilizar a coleta de dados em tempo hábil para a avaliação, foi disponibilizado no período de 16 de março a 30 de abril de 1998, um questionário auto-preenchido que foi respondido por 228 usuários que vieram ao serviço, pelo menos, pela segunda vez. Trata-se portanto de uma amostra estatisticamente não significativa, o que inviabiliza a generalização dos resultados para outros universos. Infelizmente, não se conseguiu a informação acerca do total de atendimentos (de primeira vez e retornos). Contudo, sabe-se que, em um dos serviços, os questionários foram respondidos por mais de $50 \%$ dos usuários atendidos pelo menos duas vezes.

Sob a ótica qualitativa, segundo Minayo (1992), a amostra ideal é aquela que possibilita a apreensão da totalidade do problema a ser investigado. Assim, o seu desenho passa mais pela necessidade de se contemplar as diferentes dimensões do objeto de estudo do que pela definição numérica.

Em relação às entrevistas, a participação foi voluntária e cada participante assinou um termo de consentimento livre e esclarecido, para atender à Resolução 196 de 10/10/96 do Conselho Nacional de Saúde/Ministério da Saúde. Das entrevistas analisadas, nove eram de pessoas do sexo feminino e dez do sexo masculino. As entrevistas receberam um código com três números, sendo o primeiro para a identificação do serviço, o segundo para designar se era caso de AIDS (número 1) ou portador de HIV (número 2) e o terceiro para apontar a ordem da entrevista. Em duas entrevistas do CPN não havia menção se era caso de AIDS ou portador de HIV, por isso foram codificadas como $4 \mathrm{~A}$ e $4 \mathrm{~B}$, aleatoriamente.

Em relação aos questionários foi montado um banco de dados em Dbase III Plus, trabalhando-se com freqüências simples e percentual com o programa Epi-Info versão 6.0. As variáveis grau de instrução, sexo, idade e participação nas atividades do serviço foram cruzadas pelo programa mencionado. Especificamente, para os cruzamentos de grau de instrução com outras variáveis, utilizou-se o Teste de Qui-quadrado.

Os dados qualitativos foram analisados mediante a Técnica de Análise de Conteúdo, mo- dalidade Temática. A técnica de análise temática "consiste em descobrir os 'núcleos de sentido' que compõem a comunicação e cuja presença ou freqüência de aparição podem significar alguma coisa para o objetivo analítico escolhido" (Bardin, 1979:105). Além de se buscarem respostas para questões, com esta técnica pode-se caminhar na direção da "descoberta do que está por trás dos conteúdos manifestos, indo além das aparências do que está sendo analisado" (Gomes, 1994:74).

A análise dos dados foi considerada para o conjunto dos serviços.

\section{Resultados}

\section{Características dos usuários}

dos serviços estudados

Para o conjunto dos 228 questionários respondidos, predominou o sexo masculino entre a população de usuários que utilizaram os serviços. Dos 221 informantes desta variável, $70 \%$ são do sexo masculino, numa relação de 2,3 homens para cada mulher, refletindo o perfil da epidemia no Município do Rio de Janeiro que era, em 1997, de 2:1, segundo dados do Setor de Vigilância Epidemiológica da Secretaria Municipal de Saúde do Rio de Janeiro. Percebe-se que a maioria $(64,6 \%)$ dos usuários é de adultos jovens com mais de 20 e menos de 40 anos de idade e que $47,3 \%$ tinham segundo grau ou curso superior completo ou incompleto. Com essa distribuição de anos de instrução, pode-se considerar que o usuário desses serviços têm uma boa escolaridade. A maioria dos informantes, 55,1\%, era residente no Município do Rio de Janeiro.

No que se refere à utilização dos serviços, verificou-se que, no conjunto de 218 informantes, $52,7 \%$ são atendidos há mais de um ano e somente $10,6 \%$ freqüentavam a assistência há menos de três meses.

Em síntese, entre os usuários que responderam aos questionários, houve uma predominância de homens, jovens adultos, com boa escolaridade e freqüentando o serviço há mais de um ano.

\section{Avaliação dos serviços por parte dos usuários}

\section{- A percepção do espaço físico}

Para a maioria dos usuários de cada um dos serviços, as instalações não foram consideradas como boas. Dos 217 informantes que responderam a essa questão, $59 \%$ pontuaram que 
as instalações são desconfortáveis ou pouco confortáveis e somente $9,2 \%$ consideraram-nas muito confortáveis. As principais explicações para os serviços serem considerados desconfortáveis ou pouco confortáveis se relacionaram à: ausência de bancos; existência de bancos desconfortáveis; má ventilação; ausência de bebedouro; acomodação muito pequena para a espera e para o atendimento; e, em alguns casos, falta de higiene no ambiente, principalmente nos banheiros.

No que se refere às condições de limpeza e higiene, dos 222 usuários que responderam a essa questão, 71,1\% consideraram esse item como bom e muito bom e $5 \%$ o pontuaram como ruim.

A precariedade das instalações físicas dos serviços foi um dos aspectos considerados negativos do atendimento destacado nas entrevistas. Neste sentido, há entrevistados que dizem que a "parte ruim são as instalações". Perfilando as respostas dos entrevistados acerca das dificuldades encontradas nos serviços ao lado das respostas relativas a sugestões para se melhorar o atendimento, constata-se que são comuns os depoimentos que apontam para a precariedade das instalações dos serviços. As condições de manutenção das instalações dos serviços também são apontadas ("eu acho mal ... sujeira do hospital ... falta de água ... banheiro sujo" /3.2.2). Essas falas parece que não estão se referindo a um serviço de saúde que, por definição, deveria primar pela higiene e conforto.

\section{- Acesso/utilização}

Pelas respostas dadas aos questionários, verificou-se que os serviços localizados no Município do Rio de Janeiro atendem principalmente a residentes do próprio município, com um percentual de 91,3\%. Entretanto, isso não significa que o usuário resida ou trabalhe próximo ao serviço, uma vez que, por exemplo, foi constatado que pessoas residentes em bairros como Santa Cruz e Campo Grande (Zona Oeste) estavam sendo atendidas na DIP-UERJ, em Vila Isabel (Zona Norte). Nos serviços localizados fora do Município do Rio de Janeiro percebeu-se que cerca de $50 \%$ da população atendida não residiam no município no qual se realizava o atendimento. Pode-se, valendo-se de tais dados, supor que: 1) fora da capital há carência de serviços dessa natureza, levando estes usuários a procurarem em outros municípios; 2) o estigma e a discriminação levam-nos a buscar um serviço em outro município para não serem reconhecidos.

$\mathrm{O}$ acesso dos usuários aos serviços nem sempre pode ser avaliado pelo fato de a resi- dência se localizar ou não em outro município. Assim, houve casos de pessoas que, mesmo não residindo no local onde se realizava o seu atendimento, declararam facilidade para chegar ao serviço. Reforçando esse raciocínio, pode-se mencionar que $74,2 \%$, dos 221 informantes que responderam a esta questão, consideraram que era fácil ou muito fácil chegar ao serviço de saúde. Essa facilidade é explicada, por muitos, pelo fato de haver uma boa disponibilidade de condução (linhas de ônibus e, em alguns casos, metrô). Em 79,8\% de 223 respostas, a forma de se chegar ao serviço foi por intermédio de ônibus.

Dos 187 informantes, 71,1\% participaram de todas as atividades programadas para os últimos seis meses. O sexo masculino predominou, com $71,8 \%$, no conjunto dos usuários mais presentes. A maioria desses informantes aponta a "importância do tratamento para a sua saúde" e o "amor próprio" como motivos para o comparecimento às atividades. Em termos de idade predominante dos que mais participaram das atividades, $77,1 \%$ desses tinham mais de 29 anos. Apenas oito usuários faltaram mais de duas vezes e treze faltaram duas vezes.

Comparando-se a variável grau de instrução com a variável assiduidade dos usuários nos últimos seis meses, verificou-se que, dos 184 informantes, 35,9\% participaram de todas as atividades e possuíam o 2 o grau ou nível superior. Contudo, ao analisar a relação entre essas duas variáveis, constatou-se não haver associação entre elas. Ou seja, estatisticamente, não significou que compareceu mais ao serviço o usuário com maior nível de instrução ou faltou mais aquele com menor nível de instrução.

$\mathrm{Na}$ análise em conjunto das variáveis tempo de utilização dos serviços e assiduidade dos usuários nos últimos seis meses, constatou-se que, dos 181 informantes, 38,1\% freqüentavam o serviço há mais de um ano e também participaram de todas as atividades, enquanto $15,5 \%$ freqüentaram os serviços há mais de um ano e não participaram de todas as atividades. Ao analisar essas duas variáveis, observou-se não haver relação de associação entre elas. Ou seja, estatisticamente, o fato de uma pessoa utilizar o serviço há mais de um ano não significou que tenha faltado menos ao serviço.

Para alguns usuários que foram entrevistados é a "força de vontade de viver" que faz com eles continuem comparecendo ao serviço. Um deles afirmou que passou a sentir "uma força que nunca teve na vida" (5.1.1). É esta "força" que os ajuda a enfrentar as discriminações que sofrem, causadas por "aquele preconceito das pessoas” (5.2.2). Apesar dessas situações, há 
usuários que continuam lutando, como pode ser percebido na seguinte fala: "Posso até morrer da doença ... posso morrer de outra coisa, de um tiro, de um tocaimento, da violência que anda solta por aí, mas se depender de mim, da doença eu não morro não" (5.1.2).

Para outros, não basta ter boa vontade, é preciso que haja "o atendimento, a atenção das pessoas" (1.1.1). "É ser bem tratado, ter remédios” (2.2.1). E mesmo quando esses aspectos são negligenciados, continuam freqüentando os serviços porque "tem lugares aí muito mais precários em termos de atendimento” (3.1.1).

Com base na análise dos questionários aplicados, segundo a Tabela 1, parece que a dificuldade em obter medicamentos vem mudando, uma vez que, em 202 informantes 58,9\% consideraram ser fácil conseguir medicamentos e $18,8 \%$ responderam que era muito fácil, embora alguns tenham relatado problemas em algum tipo de medicamento ou em algum momento do tratamento. Dos $22,3 \%$ que consideraram difícil e muito difícil alegaram a falta de um ou mais medicamentos, além da demora da chegada dos remédios. A obtenção de preservativos, conforme pode ser verificada, ainda nessa Tabela, foi considerada fácil e muito fácil por 85,5\% dos 179 informantes, devido ao fato de, comumente, haver uma grande disponibilidade de camisinhas no serviço. Contudo, no que se refere ao atendimento dos usuários, quando encaminhados para outros serviços de saúde, segundo $61,0 \%$ dos 154 usuários, conseguir atendimento é difícil e muito difícil. As explicações para esses conceitos atribuídos recaem, principalmente, no fato de não haver vaga e na demora do atendimento.

No conjunto das entrevistas, puderam ser destacadas dificuldades relativas ao acesso e à utilização dos serviços. Entre elas, destacaram- se: a espera pela consulta, a faltalatraso de medicamentos e demora dos resultados dos exames. "A dificuldade da espera" (1.1.2) foi recorrente nas falas dos entrevistados. Eles esperam muito para ser atendidos ("Eu perco muito tempo ... hoje foi mais de 4 horas"/1.1.2), os exames custam a chegar ("os exames demoram"/5.1.2) e há medicamentos que nem sempre estão disponíveis com regularidade ("você chega aqui e não tem medicamento e a moça da farmácia te diz só daqui a uma semana"/4.1.1).

Quanto à medicação, vale observar que "não ter o remédio" (2.1.1) foi um dos aspectos que fizeram as pessoas se afastarem dos serviços. Houve usuários que fizeram uma avaliação das causas da falta de medicação, atribuindo o problema à "parte política, mesmo, administração política ... porque eles sabem, por exemplo, que o doente de HIV é uma coisa prioritária e por que falta verba para isso? É um pouco de descaso, mesmo, das autoridades" (3.1.2).

Também no caso dos exames houve consciência das conseqüências de sua falta ou de sua espera demorada: "têm que ser feitos e com a máxima urgência porque toda urgência no caso do soropositivo, aidético, toda urgência implica vida, implica quanto mais cedo melhor pra evitar complicações, pra evitar que o estado de um paciente se agrave" (4.1.1).

Para alguns usuários, a aderência à medicação era difícil " porque tem muito efeito colateral" (1.2.2); "a hora que os comprimidos começavam a tocar no estômago, eu não conseguia segurar, eu botava tudo para fora" (4.1.1); “davam [os remédios] processo alérgico, vomitava muito" (5.1.1); "Eu tomava e vomitava quase que instantaneamente" (5.1.2); "É muito remédio. Eu tomo uma base de 20 a 21 comprimidos por dia. Anda me embrulhando o estômago ... eu não estou mais conseguindo comer" (2.1.1).

Tabela 1

Facilidade/dificuldade do usuário em conseguir medicamento, preservativo e atendimento em outros serviços quando encaminhado.

\begin{tabular}{|c|c|c|c|c|c|c|}
\hline \multirow[t]{3}{*}{ Conceitos } & \multicolumn{4}{|c|}{ Conseguir } & \multirow{2}{*}{\multicolumn{2}{|c|}{ Atendimento em outros serviços }} \\
\hline & \multicolumn{2}{|c|}{ Medicamento } & \multicolumn{2}{|c|}{ Preservativo } & & \\
\hline & $\mathrm{n}$ & $\%$ & $\mathrm{n}$ & $\%$ & $n$ & $\%$ \\
\hline Muito fácil & 38 & 18,8 & 54 & 30,2 & 10 & 6,5 \\
\hline Fácil & 119 & 58,9 & 99 & 55,3 & 50 & 32,5 \\
\hline Difícil & 34 & 16,8 & 17 & 9,5 & 63 & 40,9 \\
\hline Muito difícil & 11 & 5,5 & 9 & 5,0 & 31 & 20,1 \\
\hline Total* & 202 & 100,0 & 179 & 100,0 & 154 & 100,0 \\
\hline
\end{tabular}

* Exclui resposta ignorada. 
Apesar de um entrevistado ter afirmado que "não tem problema nenhum" (2.2.1) em tomar os remédios, a falta de aderência à medicação não se relaciona só aos efeitos colaterais. Há outros problemas que dificultam seguir adequadamente a prescrição médica: "se tivesse um pouco de orientação ... mas às vezes você explica ... e a pessoa parece que não entende ...é um negócio muito difícil” (1.1.2); “muitas pessoas não tomam porque não querem aparecer com o remédio perto das outras pessoas e não sabem como fazer isso discretamente" (5.2.2).

Um entrevistado culpabiliza o usuário pela não adesão à medicação, dizendo que isso acontece "porque a pessoa não se interessa por ela mesma" (2.2.2); outro, ainda, atribui o problema à medicação porque "cada um tem um organismo. Então, fica difícil para o médico acertar da primeira vez" (4A).

No que se refere ao uso de preservativos, destaca-se a "crítica do ir à forra". Para alguns entrevistados, um portador de HIV/AIDS não usa preservativo porque quer "ir à forra porque ele pegou” (1.1.1). Todos os usuários que trazem essa explicação o fazem reprovando tal atitude que, segundo eles, pode ocorrer por "pura maldade, pura crueldade" (5.2.2) ou "por ignorância" (3.1.1). Outras explicações para o fato de não usar preservativo são menos recriminadoras, apontando "um despreparo" (1.1.2) ou porque alguém "não se adapta à camisinha" (1.2.2), ou, ainda, as pessoas não usariam porque " $a$ cham que nunca vai acontecer com elas" (5.2.2).

A não adesão ao preservativo em todas as entrevistas foi sempre mencionada na terceira pessoa. Nenhum entrevistado admitiu o não uso. Ao contrário diziam: "Eu uso sempre" (2.2.1); "em todas as relações eu uso preservativo" (5.2.1); e os que não usavam, afirmavam que: "agora eu uso" (5.2.1). Mesmo admitindo que usam preservativo, os usuários acham que "é uma coisa meia chata ... fica um troço meio sem graça" (5.2.1) e "para falar a verdade, é estranho" (5.1.2).

Fernandes (1998), com base em estudo transversal com moradores da Rocinha, utilizando procedimento amostral, relata um aumento significativo $(\mathrm{p}<0,0001)$ da proporção de informantes que referiam utilizar preservativo de $21,9 \%$, em 1990, para 41,1\%, em 1996. Esses dados, necessariamente, não apontam para o fato de que a adesão ao uso do preservativo vem aumentando, pois podem evidenciar uma mudança de discurso ("politicamente correto").

\section{- O tempo de espera pelo atendimento}

Segundo os usuários parece não haver problemas quanto à marcação de consultas, já que, de 218 respostas, 79,3\% apontaram ser fácil e muito fácil a marcação e somente $2,3 \%$ indicaram ser muito difícil. Os principais motivos para essas opções são: em cada consulta é agendada a próxima e, geralmente, o médico faz a marcação. O tempo de espera entre um atendimento e o retorno ao serviço também foi bem avaliado, segundo a Tabela 2, pois, dos 215 informantes, $69,3 \%$ responderam ser satisfatório e muito satisfatório. Todavia, vale lembrar que $30,7 \%$ consideraram regular ou insatisfatório este item (apenas 7,0\% consideraram esse tempo insatisfatório). Ainda na Tabela 2, em relação ao tempo de espera entre a coleta do material e a entrega dos resultados de exames, percebe-se que, para 192 informantes, existe uma concentração nas respostas satisfatório e muito satisfatório, representando $56,3 \%$ das opiniões. De todos os três itens, o tempo de espera entre coleta e resultado de exame foi o pior avaliado pelos usuários. Observa-se que 14,6\% responderam que esse tempo é insatisfatório.

O predomínio dessas avaliações positivas sobre tempo de espera, no entanto, não foi percebido no conjunto das entrevistas. Há depoimentos que apontam justamente para o inverso. Tal fato pode ser explicado, parcialmente, pela própria natureza do instrumento. A entrevista possibilita, mediante interlocução, uma reflexão mais crítica e o desenvolvimento das opiniões.

\section{A percepção do atendimento em geral}

De um modo geral, os usuários se sentiram bem recebidos pela equipe de saúde. Dos 222 informantes, $87,8 \%$ consideraram que são recebidos bem e muito bem nos serviços porque se sentem tratados com simpatia, carinho e respeito. Somente $0,9 \%$ não se sentiu bem recebido.

Na Tabela 3, observa-se que os serviços, como um todo, foram avaliados pelos seus usuários, num conjunto de 215 informantes, como bom $(49,3 \%)$, muito bom $(38,6 \%)$, regular $(11,6 \%)$ e ruim $(0,5 \%)$, evidenciando uma grande aceitação do tipo de atendimento oferecido. Os percentuais de insatisfação podem, futuramente, constituir indicadores de monitoramento, dado que os parâmetros aceitáveis ainda não foram definidos pelos serviços. Analisando-se os conceitos bom e muito bom segundo a variável sexo, verificou-se, estatisticamente, não haver influência do sexo nesses conceitos de avaliação. Observou-se também 
Avaliação dos usuários acerca do tempo de espera.

\begin{tabular}{|c|c|c|c|c|}
\hline \multirow[t]{3}{*}{ Conceitos } & \multicolumn{4}{|c|}{ Tempo de espera entre } \\
\hline & \multicolumn{2}{|c|}{$\begin{array}{l}\text { Atendimento e o retorno } \\
\text { do usuário ao serviço de saúde }\end{array}$} & \multicolumn{2}{|c|}{$\begin{array}{l}\text { Coleta do material e a entrega } \\
\text { do resultado dos exames }\end{array}$} \\
\hline & $\mathrm{n}$ & $\%$ & $\mathrm{n}$ & $\%$ \\
\hline Muito satisfatório & 39 & 18,1 & 26 & 13,5 \\
\hline Satisfatório & 110 & 51,2 & 82 & 42,7 \\
\hline Regular & 51 & 23,7 & 56 & 29,2 \\
\hline Insatisfatório & 15 & 7,0 & 28 & 14,6 \\
\hline Total* & 215 & 100,0 & 192 & 100,0 \\
\hline
\end{tabular}

* Exclui resposta ignorada.

Avaliação dos serviços de saúde e do atendimento de seus setores segundo os usuários.

\begin{tabular}{|c|c|c|c|c|c|c|}
\hline Serviço/Setores & Muito bom & Bom & Regular & Ruim & Muito ruim & Total* \\
\hline Serviço de Saúde & 83 & 106 & 25 & 1 & - & 215 \\
\hline Médico & 138 & 66 & 13 & 1 & 2 & 220 \\
\hline Enfermagem & 47 & 69 & 23 & 3 & - & 142 \\
\hline Serviço Social & 93 & 60 & 9 & 1 & - & 163 \\
\hline Psicologia** & 33 & 38 & 11 & 1 & - & 83 \\
\hline Farmácia & 66 & 95 & 35 & 6 & 2 & 204 \\
\hline Odontológico*** & 13 & 16 & 10 & 2 & 8 & 49 \\
\hline Recepção & 63 & 94 & 39 & 6 & 5 & 207 \\
\hline
\end{tabular}

* Exclui resposta ignorada.

** Atendimento inexistente em dois Serviços.

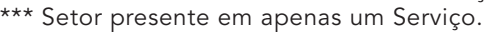

que essa avaliação por parte dos usuários não predominou em uma faixa etária específica. Constatou-se, ainda, que, independentemente do grau de instrução, os serviços foram avaliados como bom e/ou muito bom. Percebeu-se não haver associação entre a variável escolaridade e a avaliação dos serviços.

Vários entrevistados, ao serem perguntados sobre o que achavam do atendimento, expressaram várias "qualidades positivas" ("Eu acho que tem muita qualidade (...) O tratamento da gente, acho que ninguém tem o que falar" । 5.1.1). Inúmeras foram as justificativas para avaliarem positivamente o atendimento: comparação do serviço com outro ("Bem melhor do que o Posto que eu me tratava" / 1.2.2); o apoio que recebem ("dão um grande incentivo pra gente" /1.1.1); a disponibilidade da medicação (“o meu remédio está em dia, tá na hora, sempre já chegou"/1.1.1); o tratamento que é oferecido pelo profissionais ("Eu não tenho nada que me queixar de nada do atendimento das pessoas"/1.2.1).

Estudo realizado pelo Ministério da Saúde (MS, 1997c), acerca da prática do aconselhamento nos Centros de Testagem Anônima e Serviços de Assistência a Portadores de HIV/ AIDS, com 25 entrevistados, concluiu que a absoluta maioria verbalizou ter gostado do atendimento. Entre os principais motivos para essa avaliação, ressaltam-se os fatos de os profissionais prestarem aos usuários atenção e boa acolhida.

Ao serem indagados sobre o que esperavam, quando procuraram o serviço, 191 usuários manifestaram suas expectativas (cada usuário poderia espontaneamente formular mais de uma resposta). Na Tabela 4 , foram consideradas, somente, as expectativas que apareceram cinco ou mais vezes. Essas opiniões foram categorizadas e encontram-se descritas na referida Tabela. 
Tabela 4

Expectativas dos usuários acerca dos serviços.

\begin{tabular}{lccc}
\hline \multirow{2}{*}{ Expectativa } & \multicolumn{3}{c}{ Realização da expectativa } \\
& Sim & Em parte & Não \\
\hline Bom atendimento & 70 & 4 & 2 \\
Atendimento & 20 & 1 & - \\
Melhoria na saúde & 9 & 2 & - \\
Medicamento & 7 & 3 & - \\
Apoio & 6 & - & - \\
Atendimento com dignidade/respeito & 5 & - & 1 \\
Atendimento mais rápido & 4 & 2 & 10 \\
Compreensão/atenção/solidariedade & 3 & 1 & 1 \\
Atendimento ruim & 2 & 1 & \\
\hline
\end{tabular}

Obs.: Foram consideradas apenas as opiniões com freqüência igual ou superior a 5 no total. mais bem avaliados, com 93,9\% em 163 informantes e $92,7 \%$ em 220 , respectivamente, apontando os conceitos bom e muito bom. Estes conceitos também predominaram nos seguintes tipos de atendimento: psicologia $(85,6 \%)$; enfermagem $(81,7 \%)$; farmácia $(78,9 \%)$ e recepcionista $(75,8 \%)$. São inúmeros os motivos para os usuários avaliarem bem o atendimento do assistente social, médico, psicólogo e enfermeiro. Entre esses destacam-se características tais como: carinhoso, atencioso, simpático, educado e profissional. Como pode ser notado, apesar de bem avaliados, os setores de farmácia e recepção foram os que tiveram maiores críticas.

A avaliação da assistência odontológica foi feita apenas para o Município de Niterói, dado que era o único serviço que oferecia esse atendimento. O resultado dos 15 usuários que responderam a essa questão indica que $73,4 \%$ deles atribuíram conceito bom/muito bom a esse tipo de atenção. Constatou-se, em alguns serviços, a inexistência não só desse tipo de assistência, como também dos setores de psicologia e de enfermagem, do que se depreende que o princípio preconizado de atendimento multiprofissional para portadores de HIV/AIDS não é contemplado.

No que se refere à percepção dos entrevistados, há depoimentos que apontam para a importância de várias categorias profissionais no campo da saúde. Mas o atendimento médico foi muito valorizado por grande parte dos entrevistados. Para eles, é como se fosse "Deus no céu e o médico na terra”. Alguns vêem nesse profissional qualidades que ultrapassam o seu campo técnico: "O médico é a pessoa que mais ajuda psicologicamente” (1.2.1).

A valorização do médico por parte dos entrevistados confirma as respostas dos questionários. Como foi visto, entre 220 informantes dos questionários, 92,7\% apontaram os conceitos positivos para a clínica médica.

No conjunto das entrevistas, houve quem apontasse aspectos percebidos como negativos em relação aos profissionais da recepção ("às vezes, tem umas que são um pouquinho ... agressivas"/1.1.1).

Apesar desses depoimentos, nas entrevistas, em geral, foi confirmada a percepção positiva sobre a equipe de profissionais de saúde manifestada pelos 228 informantes que preencheram os questionários. Na literatura, a exemplo de Ochoa (1998), Sánchez (1998) e Sopena (1998), a boa relação entre terapeuta e paciente é vista como os dos principais fatores de adesão.

Os usuários declararam sentirem-se informados e bem informados quanto às atividades e a atendimentos oferecidos pelos serviços em $77,6 \%$ no conjunto de 210 respostas. Somente 
2,9\% se consideraram desinformados. Em geral, esta avaliação positiva é justificada pelo fato de serem bem informados quando procuram esses esclarecimentos.

\section{Considerações finais}

Como pode ser observado, de modo geral, a avaliação desses serviços foi predominantemente positiva, destacando-se: a acolhida e a qualidade da clínica médica e do serviço social; o acesso aos serviços; a obtenção de preservativos e medicamentos e a facilidade de marcar consulta. Embora com avaliação positiva, os aspectos mais criticados foram a grande espera para receber os resultados de exames e o tempo de espera para a consulta de retorno.

Os únicos aspectos avaliados negativamente foram a falta de conforto das instalações físicas, a ausência do serviço de odontologia e a dificuldade em conseguir atendimento em outros serviços referenciados (o mais negativamente avaliado).

\section{Agradecimentos}

Os autores agradecem a colaboração dos profissionais de saúde Denise Pires (Coordenação Estadual de DST/AIDS do Rio de Janeiro), Fátima Rocha (Fundação Municipal de Saúde de Niterói) e Rita Mendes Ferreira (Coordenação Municipal de DST/AIDS do Rio de Janeiro) na pesquisa de campo.

\section{Referências}

BARDIN, L., 1979. Análise de Conteúdo. Lisboa: Edições 70.

DENZIN, N. K., 1970. The Research Act. Chicago: Aldine Publishing Co.

DONABEDIAN, A., 1984. La Calidad de la Atención Médica. Definición y Métodos de Evaluación. México: La Prensa Médica Mexicana S.A.

FERNANDES, J. C. L., 1998. Evolução dos conhecimentos, atitudes e práticas relativas ao HIV/AIDS em uma população de favela do Rio de Janeiro. Cadernos de Saúde Pública, 14:575-581.

GOMES, R., 1994. A análise de dados em pesquisa qualitativa. In: Pesquisa Social: Teoria, Método e Criatividade (M. C. de S. Minayo, org.), pp. 67-80, Petrópolis: Editora Vozes.

MINAYO, M. C. S., 1991. Abordagem antropológica para avaliação de políticas sociais. Revista de Saúde Pública, 25:233-238.

MINAYO, M. C. S., 1992. O Desafio do Conhecimento: Pesquisa Qualitativa em Saúde. São Paulo: Editora Hucitec/Rio de Janeiro: Abrasco.

MINAYO, M. C. S. \& SANCHES, O., 1993. Quantitativo-qualitativo: Oposição ou complementaridade? Cadernos de Saúde Pública, 9:239-262.
As entrevistas relativizaram, ainda, a positividade das avaliações sobre a obtenção de medicamentos. A longa permanência na sala de espera aguardando a consulta e o longo período para se conseguir a consulta de retorno foram demarcados como fatores negativos por esse instrumento.

Cabe ainda refletir que esta avaliação baseou-se na ótica do usuário, sendo sua experiência e subjetividade os marcos de referência para tais dados. A avaliação positiva dos serviços (ainda que com as ressalvas críticas) pode estar referindo realmente a boa qualidade do atendimento prestado. Por outro lado, está traduzindo a "qualidade percebida", no que podem pesar as baixas expectativas de um usuário quanto aos serviços públicos.

Naturalmente, a especificidade dos serviços e das equipes confere uma qualidade ao atendimento. Respeito e acolhimento ao usuário são apontados como pontos positivos nestes serviços, aspectos que na rede pública, em geral, são deficientes.
MS (Ministério da Saúde), s/d. Serviço de Assistência Especializada - SAE. Brasília: Programa DST/ AIDS, Secretaria de Assistência à Saúde.

MS (Ministério da Saúde), 1997a. Guia para Elaboração de Relatórios de Avaliação de Desempenho para Serviços de Assistência Especializada-SAE. Brasília: Programa DST/AIDS, Secretaria de Assistência à Saúde.

MS (Ministério da Saúde), 1997b. Boletim Epidemiológico AIDS. Ano X, no 4. Brasília: Coordenação Nacional de DST/AIDS.

MS (Ministério da Saúde), 1997c. Aconselhamento: Um Desafio para a Prática em Saúde. Brasília: Secretaria de Projetos Especiais de Saúde, Coordenação Nacional de DST/AIDS. (mimeo.)

OCHOA, M. M., 1998. Intervención para la adhesión a los nuevos tratamientos. SIDA, 9:218-219.

SANCHEZ, A. G., 1998. Adhesión terapéutica. Responsabilidad compartida. SIDA, 9:237-238.

SOPENA, R. B., 1998. Adhesión terapéutica en VIH/ SIDA. SIDA, 9:193-194. 